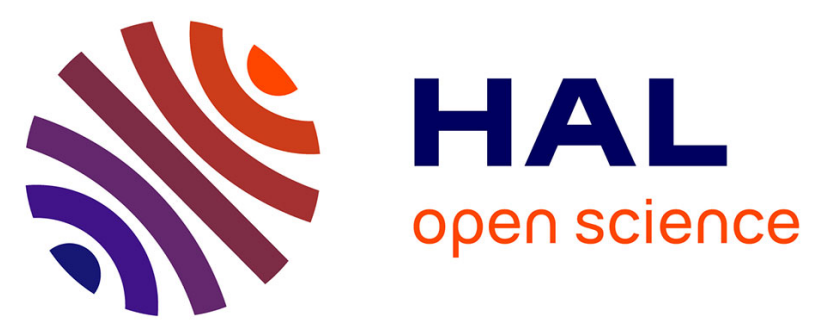

\title{
Do gender, age or life style factors affect responses to anti-muscarinic treatment in overactive bladder patients?
}

Tim Schneider, Daniela Marschall-Kehrel, Jens Ulrich Hanisch, Martin C Michel

\section{To cite this version:}

Tim Schneider, Daniela Marschall-Kehrel, Jens Ulrich Hanisch, Martin C Michel. Do gender, age or life style factors affect responses to anti-muscarinic treatment in overactive bladder patients?. International Journal of Clinical Practice, 2010, 64 (9), pp.1287. 10.1111/j.1742-1241.2010.02442.x . hal-00599539

\section{HAL Id: hal-00599539 \\ https://hal.science/hal-00599539}

Submitted on 10 Jun 2011

HAL is a multi-disciplinary open access archive for the deposit and dissemination of scientific research documents, whether they are published or not. The documents may come from teaching and research institutions in France or abroad, or from public or private research centers.
L'archive ouverte pluridisciplinaire HAL, est destinée au dépôt et à la diffusion de documents scientifiques de niveau recherche, publiés ou non, émanant des établissements d'enseignement et de recherche français ou étrangers, des laboratoires publics ou privés. 


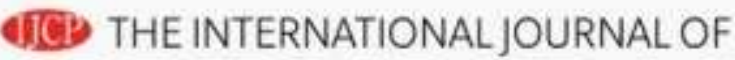 CLINICAL PRACTICE}

\section{Do gender, age or life style factors affect responses to anti- muscarinic treatment in overactive bladder patients?}

\begin{tabular}{|c|c|}
\hline Journal: & International Journal of Clinical Practice \\
\hline Manuscript ID: & IJCP-02-10-0091.FT10.R1 \\
\hline Manuscript Type: & Original Paper \\
\hline $\begin{array}{r}\text { Date Submitted by the } \\
\text { Author: }\end{array}$ & 15-Mar-2010 \\
\hline Complete List of Authors: & $\begin{array}{l}\text { Schneider, Tim; Praxisklinik Urologie Rhein-Ruhr } \\
\text { Marschall-Kehrel, Daniela; Urological Practice } \\
\text { Hanisch, Jens Ulrich; Bayer Vital, Dept. Non-Interventional Studies } \\
\text { Michel, Martin; AMC, University of Amsterdam, Dept. Pharmacology } \\
\text { \& Pharmacotherapy }\end{array}$ \\
\hline Specialty area: & \\
\hline
\end{tabular}

\section{s scholaroNE}

Manuscript Central 
Do gender, age or life style factors affect responses to anti-muscarinic treatment in overactive bladder patients?

Tim Schneider ${ }^{\mathrm{a}}$, Daniela Marschall-Kehrel ${ }^{\mathrm{b}}$, Jens U. Hanisch ${ }^{\mathrm{c}}$, Martin C. Michel ${ }^{\mathrm{d}}$

${ }^{\mathrm{a}}$ Praxisklinik Urologie Rhein-Ruhr, Mülheim, Germany

${ }^{\mathrm{b}}$ Urological Practice, Frankfurt, Germany

${ }^{c}$ Dept. Non-Interventional Studies, Bayer Vital GmbH, Wuppertal, Germany

${ }^{\mathrm{d}}$ Dept. Pharmacology \& Pharmacotherapy, Academic Medical Center, Amsterdam, Netherlands

Address for correspondence:

Prof. Martin C. Michel

Dept. Pharmacology \& Pharmacotherapy

Academic Medical Center

Meibergdreef 15

1105 AZ Amsterdam, Netherlands

phone: $+31-20-566-6762$

fax: $+31-20-696-5976$

mail: m.c.michel@amc.nl

\section{$\underline{\text { Author contributions }}$}

All authors jointly developed the idea for the analyses underlying the present manuscript. The data had been collected by 1155 German physicians and were analyzed by a contract research 
organization based upon a statistical analysis plan jointly developed by all authors. The manuscript was drafted by Tim Schneider and Martin C. Michel and critically revised for scientific content by Daniela Marschall-Kehrel and Jens U. Hanisch. Bayer Vital had funded the underlying study as well as the present analyses. Authors had access to the study data that support the publication.

Disclosures: Bayer Vital had funded the underlying study as well as the present analyses. Tim Schneider has received consultancy and/or speaker honoraria from Astellas, Bayer and Pfizer, Daniela Marschall-Kehrel has received consultancy honoraria from Allergan, Apogepha, Astellas, Bayer, Ferring, Lilly, and Pfizer. Jens U. Hanisch is an employee and stock owner of Bayer. Martin C. Michel has received research funds, speaker and/or consultancy honoraria from Allergan, Astellas, Bayer, Lilly and Pfizer. 


\section{ABSTRACT}

Aims: Gender, age, obesity, smoking, and alcohol or caffeine intake have been shown or proposed to be risk factors for the prevalence and/or severity of the overactive bladder symptom complex $(\mathrm{OAB})$ or related parameters. We have explored whether any of these factors affects the therapeutic response to a muscarinic receptor antagonist during routine clinical use.

Methods: Data were analyzed from 3766 OAB patients (77.1\% female, age $62.6 \pm 12.8$ years) participating in an observational, open-label post-marketing surveillance study of the safety and efficacy of darifenacin. Multiple logistic regression models were applied to explore the effect of potential $\mathrm{OAB}$ risk factors on the darifenacin treatment-associated improvement of OAB symptoms, patient's subjective rating of bladder problems, and global efficacy and tolerability.

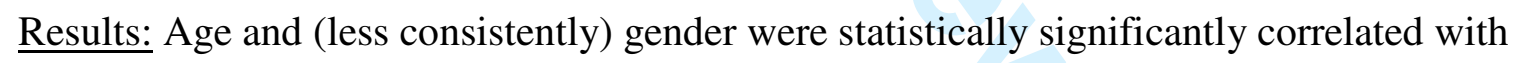
efficacy parameters, but the extent of their impact was judged to be too small to be clinically relevant. Except for a very small effect of body mass index on urgency episode improvement, none of the life style-associated factors had significant effects on the efficacy of darifenacin. Except for a very small age effect, none of the potential risk factors had significant effects on global tolerability.

Discussion and conclusions: We conclude that the efficacy and tolerability of a muscarinic receptor antagonist such as darifenacin is largely independent of potential OAB risk factors such as gender, age, obesity, smoking and alcohol or caffeine intake. 
Key words: overactive bladder, urinary incontinence, gender, age, obesity, smoking, alcohol, caffeine, darifenacin

\section{What is already known about this topic?}

Gender, age, obesity, smoking, and alcohol or caffeine intake have been shown or proposed to be risk factors for the prevalence and/or severity of the overactive bladder symptom complex $(\mathrm{OAB})$ or related parameters but their possible effect on treatment outcomes is unknown.

\section{$\underline{\text { What does this article add? }}$}

Gender, age, obesity, smoking, and alcohol or caffeine intake apparently have little effect on the results of $\mathrm{OAB}$ treatment with a muscarinic antagonist. 
INTRODUCTION

The overactive bladder symptom complex $(\mathrm{OAB})$ is defined by the presence of urgency, with or without incontinence, frequently accompanied by urinary frequency and nocturia (1). It is a very common condition in the general adult population (2-4) with major adverse effects on quality of life of the afflicted patients and considerable costs to society. While the causes of $\mathrm{OAB}$ and specifically urgency remain largely unclear (5), a number of risk factors have been demonstrated or proposed. A major risk factor is ageing, as the prevalence of OAB consistently increases with age $(2-4,6)$. While gender does not appear to be a risk factor for the presence of $\mathrm{OAB}$ in population-based studies (2-4), the vast majority of patients receiving OAB treatment are women $(7,8)$.

Additionally, a number of life-style factors have been proposed to be risk factors for OAB. Earlier studies have reported obesity, typically assessed as a high body mass index (BMI), (912) or smoking $(10,11)$ to be risk factors for incontinence in general but did not differentiate between stress and urgency incontinence. While obesity and smoking (via the associated frequent coughing) are pathophysiologically plausible risk factors for stress incontinence, their link to $\mathrm{OAB}$ or urgency incontinence is less clear. Nevertheless, both obesity and, to a lesser extent, smoking have also been linked as risk factors to urgency incontinence (13), detrusor instability (14) and the classical albeit non-specific OAB symptom nocturia (15) although such associations have not been confirmed for both factors in all studies $(15,16)$. An increased intake of alcohol and/or caffeine may affect voiding patterns based upon the diuretic effects of these agents. While increased intake of alcohol and/or caffeine have been proposed as risk factors for $\mathrm{OAB}$ or detrusor instability, the existing data are equivocal (14-17). The life style-associated factors are of particular interest as they are modifiable, i.e. theoretically offer 
the possibility to improve the condition (18). For example, a recent randomized trial has demonstrated that alterations of fluid intake can affect symptoms in OAB patients (19) whereas weight loss may improve incontinence in obese patients (20).

Muscarinic receptor antagonists are the main treatment option for OAB patients $(21,22)$. While they have consistently been shown to be superior to placebo, it remains unclear how potential risk factors for OAB may affect the treatment response to these drugs. For example, age may alter the expression of muscarinic receptors in the bladder and its responsiveness to muscarinic receptor ligands (23), but some clinical data indicate that age may have limited effect on treatment responses $(7,24)$. Whether modifiable factors such as obesity, smoking or alcohol and caffeine ingestion may affect the therapeutic response to muscarinic antagonists has not been investigated to our knowledge.

Darifenacin is a muscarinic receptor antagonist with efficacy in the treatment of OAB symptoms in several randomized, double-blind, placebo-controlled studies (25-27). Against the above background, we have used the database from a recent large observational study of the safety and efficacy of darifenacin to explore possible roles of gender, age and life-style factors in the clinical response to a muscarinic receptor antagonist.

\section{MATERIAL AND METHODS}

This manuscript describes a post-hoc analysis of a large, open-label, observational study into the safety and efficacy of darifenacin which had been performed as part of its post-marketing surveillance in Germany. Thus, no specific inclusion and exclusion criteria were applied other than a minimum age of 18 years and the recommendations from the Summary of Product 
Characteristics for darifenacin. The participating 1155 physicians (including $81.0 \%$ boardcertified and office-based urologists, $13.8 \%$ general practitioners) were asked to systematically record their observation of patients receiving darifenacin based upon their medical judgment. Based upon the package insert, recommended darifenacin doses were 7.5 and $15 \mathrm{mg}$ q.d. The planned observation time was 12 weeks. At the time the study was performed, ethical committee approval, registration in clinical trials databases or written patient consent were neither required nor recommended for purely observational studies, such as this one, in Germany.

The study included a total of 5821 patients, of which 3766 patients completed a 3-day micturition diary both pre-treatment and at least once after initiation of treatment, apparently reflecting clinical practice in Germany. Our analysis is based upon the latter group only to ascertain validity of the reported voiding data, but the demographic characteristics including the presence of potential risk factors were very similar in the total population and those with documented micturition diaries (data not shown). Our analysis is based upon the office visit prior to and at the end of the observational period; in cases of premature study discontinuation, the data from the last available visit were used in a last-observation-carried-forward manner.

At the initial visit, a medical history including questions about the possible risk factors of smoking, alcohol and caffeine use was recorded in a standardized manner. BMI was calculated from the height and weight of the patient. The physician applied qualitative scoring to record smoking status (never smoked, past smoker and present smoker), alcohol consumption (abstinent, light, moderate, strong) and caffeine intake (none, moderate, strong) based upon information provided by the patient. This information was used to stratify the population for all further analyses, but no instructions were given on how to rate these factors 
in order not to minimize interference with the observational character of the study. Moreover, at each visit the intensity of OAB symptoms (based upon diaries), a problem assessment (“The overactive bladder presently causes no/mild/moderate/severe problems"), possible adverse events and prescribed darifenacin dose were recorded. At the final visit, global physician assessments of efficacy and tolerability and patient-reported satisfaction with treatment and alteration in the ability to hold urine were also documented.

Data handling was performed by a contract research organization (Dr. Schauerte, Oberhaching, Germany). Baseline data are presented as means \pm SD of absolute values of $n$ patients. In line with previous similar analyses (28), treatment data are presented as \% changes for OAB symptoms. Adverse events were coded according to MedDRA Version 8.1. Descriptive statistical analysis was performed with the SAS for Windows program package (version 9.1). For interval-scaled variables, multiple ordinary least squares regression was applied, and logistic regression models for dichotomous dependent variables. As independent variables, BMI $\left(\mathrm{kg} / \mathrm{m}^{2}\right)$, age (years), and factors of gender, alcohol consumption, smoking and caffeine intake were entered into the models to explore the statistical contribution of these factors to treatment responses. A p $<0.05$ was considered significant.

\section{RESULTS}

The study population had an average age of $62.6 \pm 12.8$ years, body weight of $75.8 \pm 12.0 \mathrm{~kg}$, height of $168.5 \pm 7.2 \mathrm{~cm}$ and BMI of $26.7 \pm 4.0 \mathrm{~kg} / \mathrm{m}^{2}$. Among them $77.1 \%$ were female, $75.3 \%$ non-smokers, $16.8 \%$ present smokers and $7.9 \%$ past smokers. Abstinence, light, moderate and strong alcohol consumption was reported by $28.7 \%, 58.3 \%, 12.6 \%$ and $0.5 \%$ of participants, respectively (the latter two being pooled for all further analysis). No, moderate or 
strong caffeine consumption was reported by $11.8 \%, 80.6 \%$ and $7.6 \%$, respectively. The patients reported OAB symptoms for $<1,1-5,6-10$ and $>10$ years in $26.0 \%, 54.7 \%, 14.2 \%$ and $5.2 \%$, respectively. $56.4 \%$ of patients had received some type of OAB treatment in the past. At enrolment $31.7 \%$ used pads, $27.9 \%$ toilet training, $34.4 \%$ pelvic floor exercises and 4.2\% electrostimulation (multiple nominations possible), whereas no adjunct treatments for voiding dysfunction were reported by $32.3 \%$. The prevalence of concomitant urological medication (WHO Drug Directory class G04) was $<5 \%$. A darifenacin starting dose of 7.5 and $15 \mathrm{mg}$ q.d. was used in $97.2 \%$ and $2.8 \%$, respectively. The episode frequency of urgency, incontinence, micturitions and nocturia as well as problem assessment before and after treatment are shown in figure 1. Ability to hold urine after treatment as compared to the start of treatment was rated as significantly longer, longer, same or shorter by $46.9 \%, 40.2 \%$, $12.2 \%$ and $0.6 \%$ of patients, respectively. The global efficacy of treatment was rated as very good, good, moderate or insufficient by $42.7 \%, 36.1 \%, 10.3 \%$ and $10.9 \%$, respectively. At the end of the observation period $84.7 \%$ and $15.3 \%$ of patients received the 7.5 and $15 \mathrm{mg}$ dose of darifenacin, respectively. Gender and smoking status had little association with dose selection, whereas greater age ( $15 \mathrm{mg}$ used by $14.4 \%$ aged $<50$ years vs. $17.1 \%>75$ years), BMI $\left(13.9 \%\right.$ for $<25 \mathrm{~kg} / \mathrm{m}^{2}$ vs. $21.7 \%$ for $>30 \mathrm{~kg} / \mathrm{m}^{2}$ ) or alcohol consumption $(15.7 \%$ for abstinent patients vs. $18.3 \%$ for those reporting moderate-strong consumption) were associated with a higher probability of receiving the $15 \mathrm{mg}$ dose; in contrast, coffee consumption of any degree was associated with a smaller probability for receiving the higher dose (14.6\% vs. $20.5 \%)$.

Based upon the data from the overall population, multiple regression models were applied to explore the roles of various factors in treatment-associated improvements of urgency, incontinence, micturition and nocturia episodes (Table 1). The baseline episode frequency of a symptom was the strongest predictor of its treatment-associated improvement (Table 1). 
Increasing age was significantly correlated to decreased improvements in urgency, incontinence, daytime micturition and nocturia episodes, but the magnitude of the age effect was very small relative to the overall treatment effect. For example, darifenacin treatment was associated with a reduction in the number of urgency episodes/24 h from $9.1 \pm 5.8$ to $5.0 \pm 4.1$, whereas each additional year of age was statistically associated with a decreased improvement of 0.01 episodes. Female gender did not significantly affect treatment-associated improvements of incontinence episodes but was associated with a statistically greater improvement of urgency, micturition and nocturia episodes (Table 1). However, the correlation of gender with the overall improvement was relatively weak. Except for a small but significant effect of increasing BMI on the improvement of urgency episodes, none of the life style factors significantly affected improvements of any of the four OAB symptoms (Table 1).

In line with the results from the above linear models regarding OAB symptoms, increasing age was also associated with a significantly smaller likelihood for a positive problem assessment and global efficacy or tolerability rating, whereas female gender was associated with a significantly greater likelihood for a positive problem assessment or global efficacy rating, but here as well effect sizes were small (Table 2). None of the life style factors significantly affected problem assessment or global efficacy (Table 2).

In line with post-marketing studies on other muscarinic receptor antagonists $(7,8,29)$, adverse events were noted in only $2.7 \%$ of patients and consisted largely of dry mouth and constipation. Accordingly, the global tolerability was rated as very good, good, moderate and poor by $50.1 \%, 43.6 \%, 4.6 \%$ and $1.8 \%$ of patients, respectively, and the overall patient satisfaction was reported as very satisfied, satisfied or not satisfied by $42.4 \%, 44.9 \%$ and 
$12.7 \%$, respectively. In multiple linear models none of the life style factors was associated with an altered global tolerability rating (Table 2).

\section{DISCUSSION}

Age as well as several life style factors have been reported to be potential risk factors for $\mathrm{OAB}$ (see introduction). While female gender has not been established as a risk factor for $\mathrm{OAB}$, the majority of patients receiving $\mathrm{OAB}$ treatment are female $(7,8)$. Limited clinical data have explored the effects of age and gender on treatment responses in OAB patients (7, 24), but the potential effects of life-style factors have not been reported to our knowledge.

\section{Critique of methods}

Our analysis is based upon an observational, large-scale, open-label study on the efficacy and tolerability of darifenacin in routine clinical use. In the absence of a placebo group, observational data do not allow for absolute conclusions about the safety and efficacy of darifenacin. However, multiple placebo-controlled studies have already demonstrated the absolute efficacy and tolerability of darifenacin (25-27). On the other hand, observational studies have proven useful for comparisons of relative efficacy and tolerability between patient groups of OAB patients $(7,8,24)$. An observational study from routine clinical use may be particularly advantageous to explore the roles of potential OAB risk factors in treatment responses, because the strict inclusion and exclusion criteria of randomized controlled studies may limit variability of these factors in the study population, particularly for life style factors. Moreover, the expected inter-relatedness of several risk factors, e.g. of smoking and alcohol use, requires large patient numbers to yield the necessary statistical 
power for detection of minor effects. Such large patient numbers are easier to collect from observational studies.

On the other hand, for reason of practicality, assessments in post-marketing surveillance studies are somewhat cruder than in controlled clinical or dedicated epidemiological studies. For example, the quantitative assessment of life style factors is everything but straightforward, particularly when it comes to factors such as alcohol consumption where many patients may provide somewhat "beautified" responses. Given the practical limitations of a large and noninterventional study we had chosen for an assessment graded by the physician into 3-4 categories. While this may be suboptimal for a dedicated study into e.g. alcohol consumption, it reflects a necessary compromise between the scientifically desirable and the practically feasible. Finally, we have also used physician ratings of global efficacy and tolerability, as particularly the latter has proven to yield a statistically sensitive means to pick up differences in tolerability despite a typically reported incidence of adverse events in observational studies in $\mathrm{OAB}(7,8)$. These specific advantages and limitations should be kept in mind in the interpretation of our data.

\section{$\underline{\text { Treatment results }}$}

Age not only is a well-established risk factor for OAB (2-4) but is also known to affect the expression of muscarinic receptors in the bladder and other tissues including salivary glands and heart $(23,30)$. Until now only limited data on the effects of age on treatment results in OAB patients had been reported: One large observational study with tolterodine demonstrated a statistically significant but probably clinically irrelevant adverse effect of age on treatmentassociated symptom improvement and global efficacy (7). On the other hand, this small 
Although women receive muscarinic antagonist treatment of OAB symptoms more frequently than men, the prevalence of $\mathrm{OAB}$ does not exhibit major gender differences (2-4) and muscarinic receptor expression in the bladder is similar in both genders across multiple species (23). An observational study with tolterodine has reported that gender may have statistically significant effects on therapeutic efficacy, which are very small and not seen for all OAB symptoms; moreover, gender did not significantly affect the tolerability of tolterodine (7). Gender did not affect the efficacy or tolerability of solifenacin in a similar study (24). In line with these observations, the present study found very similar effects in both genders upon treatment with darifenacin. Therefore, it appears that muscarinic antagonists as a class are similarly effective and tolerated in male and female OAB patients.

The major novel aspect of the present analysis was the exploration of potential effects of life style factors on the efficacy and tolerability of a muscarinic antagonist in the treatment of 
OAB. While a high BMI has been demonstrated as a risk factor for OAB (see introduction), our data demonstrate that it does not affect the efficacy or tolerability of darifenacin in a clinically relevant manner. This is interesting as obesity and treatment response could not only interfere pathophysiologically but also a greater body weight would be associated with a smaller drug exposure per kg body weight. Accordingly, a greater BMI was associated with a greater likelihood for a higher darifenacin dose in the present study. While the role of alcohol, smoking and caffeine intake as risk factors for $\mathrm{OAB}$ remains under debate (see introduction), neither affected the efficacy or tolerability of darifenacin in the present study, although a trend for a higher darifenacin dose with greater alcohol (but not smoking or coffee) consumption may have masked an effect of alcohol on treatment.

\section{CONCLUSION}

In conclusion, the available data show that age, gender and several life style factors have no clinically relevant impact on the efficacy or tolerability of the muscarinic receptor antagonist darifenacin. Thus, muscarinic receptor antagonists can be expected to be similarly effective and tolerated regardless of the presence of such factors. While only limited data are available with regard to the modification of life style factors to improve OAB symptoms $(19,20)$, we propose that an optimal therapeutic approach to $\mathrm{OAB}$ will involve both medical treatment and life style advice.

Acknowledgements: Bayer Vital had funded the underlying study as well as the present analyses. 


\section{REFERENCES}

1 Abrams P, Cardozo L, Fall M, Griffiths D, Rosier P, Ulmsten U, et al. The standardisation of terminology of lower urinary tract function: report from the standardisation sub-committee of the International Continence Society. Neurourol Urodyn 2002; 21: 167-178.

2 Milsom I, Abrams P, Cardozo L, Roberts RG, Thüroff JW, Wein AJ. How widespread are the symptoms of an overactive bladder and how are they managed? A populationbased prevalence study. BJU Int 2001; 87: 760-766.

3 Stewart WF, van Rooyen JB, Cundiff GW, Abrams P, Herzog AR, Corey R, et al. Prevalence and burden of overactive bladder in the United States. World J Urol 2003; 20: $327-336$.

4 Irwin DE, Milsom I, Hunskaar S, Reillly K, Kopp Z, Herschorn S, et al. Populationbased survey of urinary incontinence, overactive bladder, and other lower urinary tract symptoms in five countries: results of the EPIC study. Eur Urol 2006; 50: 1306-1315.

5 Michel MC, Chapple CR. Basic mechanisms of urgency: basic and clinical evidence. Eur Urol 2009; 56: 298-308.

6 Goepel M, Hoffmann J, Piro M, Rübben H, Michel MC. Prevalence and physician awareness of symptoms of urinary bladder dysfunction. Eur Urol 2002; 41: 234-239.

7 Michel MC, Schneider T, Krege S, Goepel M. Do gender or age affect the efficacy and safety of tolterodine? J Urol 2002; 168: 1027-1031. 
8 Michel MC, Wetterauer U, Vogel M, de la Rosette JJMCH. Cardiovascular safety and overall tolerability of solifenacin in routine clinical use. Drug Safety 2008; 31: 505514.

9 Brown JS, Seeley DG, Fong J, Black DM, Ensrud KE, Grady D. Urinary incontinence in older women: who is at risk? Obstet Gynecol 1996; 87: 715-721.

10 Espino DV, Palmer RF, Miles TP, Mouton CP, Lichtenstein MJ, Markides KP. Prevalence and severity of urinary incontinence in elderly Mexican-American women. J Am Geriatr Soc 2003; 51: 1580-1586.

11 Hannestad YS, Rortveit G, Daltveit AK, Hunskaar S. Are smoking and other lifestyle factors associated with female urinary incontinence? The Norwegian EPINCONT study. BJOG 2003; 110: 247-254.

12 Melville JL, Katon W, Delaney K, Newton K. Urinary incontinence in US women. A population-based study. Arch Intern Med 2005; 165: 537-542.

13 Dallosso HM, McGrother CW, Matthews RJ, Donaldson MMK. The association of diet and other lifestyle factors with overactive bladder and stress incontinence: a longitudinal study in women. BJU Int 2003; 92: 69-77.

14 Arya LA, Myers DL, Jackson ND. Dietary caffeine intake and the risk for detrusor instability: a case-control study. Obstet Gynecol 2000; 96: 85-89.

15 Shiri R, Hakama M, Häkkinen J, Auvinen A, Huhtala H, Tammela TLJ, et al. The effects of lifestyle factors on the incidence of nocturia. J Urol 2008; 180: 2059-2062. 
16 Brown JS, Grady D, Ouslander JG, Herzog AR, Varner E, Posner SF. Prevalence of urinary incontinence and associated risk factors in postmenopausal women. Obstet Gynecol 1999; 94: 66-70.

17 Dallosso HM, Matthews RJ, McGrother CW, Donaldson MMK, Shaw C. The association of diet and other lifestyle factors with the onset of overactive bladder: a longitudinal study in men. Public Health Nutr 2004; 7: 885-891.

18 Wyman JF, Burgio KL, Newman DK. Practical aspects of lifestyle modifications and behavioural interventions in the treatment of overactive bladder and urgency urinary incontinence. Int J Clin Pract 2009; 63: 1177-1191.

19 Hashim H, Abrams P. How should patients with an overactive bladder manipulate their fluid intake? BJU Int 2008; 102: 62-66.

20 Natarajan V, Master V, Ogan K. Effects of obesity and weight loss in patients with nononcological urological disease. J Urol 2009; 181: 2424-2429.

21 Chapple CR, Khullar V, Gabriel Z, Muston D, Biton CE, Weinstein D. The effects of antimuscarinic treatments in overactive bladder: an update of a systematic review and meta-analysis. Eur Urol 2008; 54: 543-562.

22 Novara G, Galfano A, Secco S, D'Elia C, Cavalleri S, Ficarra V, et al. A systematic review and meta-analysis of randomized controlled trials with antimuscarinic drugs for overactive bladder. Eur Urol 2008; 54: 740-764.

23 Michel MC, Barendrecht MM. Physiological and pathological regulation of the autonomic control of urinary bladder contractility. Pharmacol Ther 2008; 117: 297 312. 
24 Witte LPW, Peschers U, Vogel M, de la Rosette JJMCH, Michel MC. Does the number of previous vaginal deliveries affect overactive bladder symptoms or their response to treatment? LUTS 2009; 1: 82-87.

25 Chapple C, Steers W, Norton P, Millard R, Kralidis G, Glavind K, et al. A pooled analysis of three phase III studies to investigate the efficacy, tolerability and safety of darifenacin, a muscarinic $\mathrm{M}_{3}$ selective receptor antagonist, in the treatment of overactive bladder. BJU Int 2005; 95: 993-1001.

26 Foote J, Glavind K, Kralidis G, Wyndaele J-J. Treatment of overactive bladder in the older patient: pooled analysis of three phase III studies of darifenacin, an $\mathrm{M}_{3}$ selective receptor antagonist. Eur Urol 2005; 48: 471-477.

27 Michel MC, Oelke M, Zinner N. Novel muscarinic antagonists to treat incontinence and/or overactive bladder. Drug Discov Today: Ther Strat 2005; 2: 1-6.

28 Michel MC, Oelke M, Goepel M, Beck E, Burkart M. Relationships among symptoms, bother, and treatment satisfaction in overactive bladder patients. Neurourol Urodyn 2007; 26: 190-195.

29 Michel MC, de la Rosette JJMCH, Piro M, Schneider T. Comparison of symptom severity and treatment response in patients with incontinent and continent overactive bladder. Eur Urol 2005; 48: 110-115.

30 Brodde O-E, Michel MC. Adrenergic and muscarinic receptors in the human heart. Pharmacol Rev 1999; 51: 651-689. 


\section{LEGENDS TO THE FIGURES}

Figure 1: OAB symptoms and problem assessment at baseline and after treatment with darifenacin. Data are means \pm SD except for problem assessment.
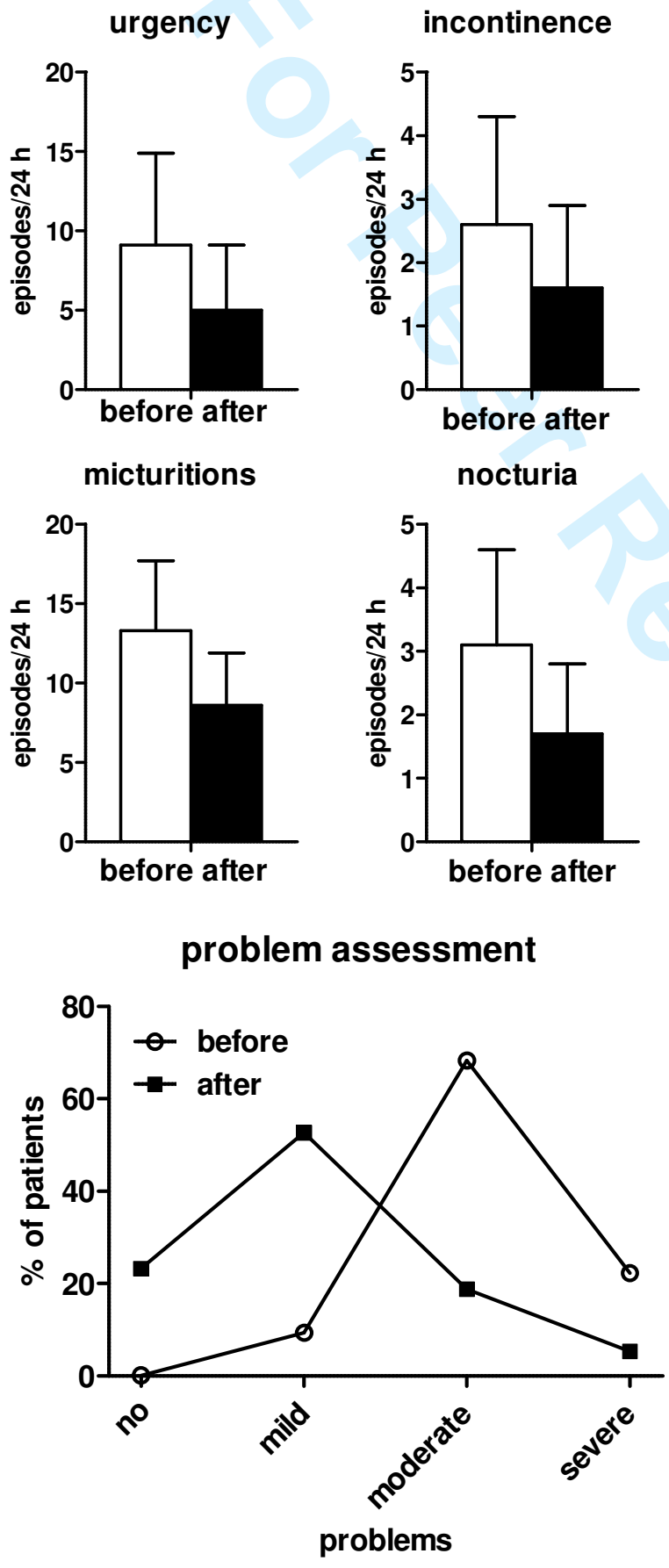


\section{TABLES}

Table 1: Multiple regression models exploring the effects of potential risk factors for darifenacin treatment-associated improvement of OAB symptoms. A positive number for the parameter indicates a numerically worse result, and a negative number a numerically better result. Data are means \pm SD. P-values are based on a Wald Chi-square test.

\begin{tabular}{|c|c|c|}
\hline 28 & Parameter estimate & p-value \\
\hline \multicolumn{3}{|c|}{ Urgency episode improvement } \\
\hline Age, per year & $0.0127 \pm 0.0045$ & 0.0049 \\
\hline Gender, relative to male & $-0.4416 \pm 0.1379$ & 0.0014 \\
\hline BMI, per $\mathrm{kg} / \mathrm{m}^{2}$ & $0.0298 \pm 0.0146$ & 0.0421 \\
\hline Previous smoking, relative to none & $-0.0128 \pm 0.2124$ & 0.9521 \\
\hline Current smoking, relative to none & $0.2335 \pm 0.1575$ & 0.1382 \\
\hline Mild alcohol, relative to none & $-0.1812 \pm 0.1325$ & 0.1715 \\
\hline Moderate to severe alcohol, relative to none & $-0.1920 \pm 0.2008$ & 0.3391 \\
\hline Moderate caffeine, relative to none & $-0.1372 \pm 0.1747$ & 0.4325 \\
\hline Severe caffeine, relative to none & $0.4276 \pm 0.2647$ & 0.1063 \\
\hline Baseline urgency, per episode & $0.5047 \pm 0.0097$ & $<0.0001$ \\
\hline \multicolumn{3}{|c|}{ Incontinence episode improvement } \\
\hline Age, per year & $0.0047 \pm 0.0020$ & $\mathbf{0 . 0 2 1 0}$ \\
\hline Gender, relative to male & $-0.0011 \pm 0.0659$ & 0.9863 \\
\hline BMI, per $\mathrm{kg} / \mathrm{m}^{2}$ & $0.0116 \pm 0.0065$ & 0.0727 \\
\hline Previous smoking, relative to none & $-0.1764 \pm 0.1016$ & 0.0827 \\
\hline Current smoking, relative to none & $0.0994 \pm 0.0708$ & 0.1607 \\
\hline
\end{tabular}




\begin{tabular}{|c|c|c|}
\hline Mild alcohol, relative to none & $0.0261 \pm 0.0586$ & 0.6562 \\
\hline Moderate to severe alcohol, relative to none & $0.0803 \pm 0.0903$ & 0.3739 \\
\hline Moderate caffeine, relative to none & $-0.1041 \pm 0.0773$ & 0.1779 \\
\hline Severe caffeine, relative to none & $0.1131 \pm 0.1203$ & 0.3470 \\
\hline Baseline incontinence, per episode & $0.3948 \pm 0.0133$ & $<0.0001$ \\
\hline \multicolumn{3}{|c|}{ Micturition episode improvement } \\
\hline Age, per year & $0.0190 \pm 0.0042$ & $<0.0001$ \\
\hline Gender, relative to male & $-0.3316 \pm 0.1247$ & 0.0079 \\
\hline BMI, per $\mathrm{kg} / \mathrm{m}^{2}$ & $0.0219 \pm 0.0134$ & 0.1012 \\
\hline Previous smoking, relative to none & $0.0224 \pm 0.1897$ & 0.9060 \\
\hline Current smoking, relative to none & $0.1535 \pm 0.1445$ & 0.2880 \\
\hline Mild alcohol, relative to none & $-0.1047 \pm 0.1215$ & 0.3889 \\
\hline Moderate to severe alcohol, relative to none & $0.0744 \pm 0.1842$ & 0.6861 \\
\hline Moderate caffeine, relative to none & $-0.2001 \pm 0.1597$ & 0.2104 \\
\hline Severe caffeine, relative to none & $0.2477 \pm 0.2430$ & 0.3081 \\
\hline Baseline micturitions, per episode & $0.4623 \pm 0.0115$ & $<0.0001$ \\
\hline \multicolumn{3}{|c|}{ Nocturia episode improvement } \\
\hline Age, per year & $0.0097 \pm 0.0014$ & $<0.0001$ \\
\hline Gender, relative to male & $-0.1638 \pm 0.0423$ & 0.0001 \\
\hline BMI, per $\mathrm{kg} / \mathrm{m}^{2}$ & $0.0085 \pm 0.0045$ & 0.0608 \\
\hline Previous smoking, relative to none & $-0.0317 \pm 0.0645$ & 0.6231 \\
\hline Current smoking, relative to none & $0.0897 \pm 0.0491$ & 0.0677 \\
\hline Mild alcohol, relative to none & $-0.0693 \pm 0.04121$ & 0.0927 \\
\hline Moderate to severe alcohol, relative to none & $-0.0659 \pm 0.0626$ & 0.2925 \\
\hline
\end{tabular}




\begin{tabular}{|l|c|r|}
\hline Moderate caffeine, relative to none & $-0.0910 \pm 0.0544$ & 0.0946 \\
\hline Severe caffeine, relative to none & $0.0454 \pm 0.0826$ & 0.5828 \\
\hline Baseline nocturia, per episode & $0.3880 \pm 0.0120$ & $<0.0001$ \\
\hline
\end{tabular}


Table 2: Logistic regression models exploring the effects of potential risk factors for darifenacin treatment-associated improvement of problem assessment and the global efficacy and tolerability of darifenacin. Data are shown as odds ratios for a beneficial effect (greater improvement of problem assessment, very good or good global efficacy and tolerability) with 95\% confidence intervals in parentheses (intervals excluding unity indicate statistical significance). In this regard an odds ratio $>1$ indicates a numerically better result, and an odds ratio $<1$ a numerically worse result.

\begin{tabular}{|l|r|r|r|}
\hline & $\begin{array}{c}\text { Problem assessment } \\
\text { (improvement vs. no }\end{array}$ & $\begin{array}{r}\text { Efficacy } \\
\text { (very good/good vs. } \\
\text { improvement })\end{array}$ & $\begin{array}{c}\text { Tolerability } \\
\text { (very good/good vs. } \\
\text { moderate/poor) }\end{array}$ \\
\hline Age, per year & $\mathbf{0 . 9 8 1}(\mathbf{0 . 9 7 5} ; \mathbf{0 . 9 8 8})$ & $\mathbf{0 . 9 7 8}(\mathbf{0 . 9 7 0} ; \mathbf{0 . 9 8 5})$ & $\mathbf{0 . 9 8 2}(\mathbf{0 . 9 7 1 ; ~ 0 . 9 9 3 )}$ \\
\hline Gender, relative to male & $\mathbf{1 . 3 1 3}(\mathbf{1 . 0 8 7} ; \mathbf{1 . 5 8 7})$ & $\mathbf{1 . 3 9 6}(\mathbf{1 . 1 3 5} ; \mathbf{1 . 7 1 6})$ & $1.047(0.746 ; 1.471)$ \\
\hline BMI, per kg/m ${ }^{2}$ & $1.010(0.990 ; 1.032)$ & $0.979(0.957 ; 1.001)$ & $0.998(0.963 ; 1.034)$ \\
\hline Previous smoking, relative to none & $1.114(0.823 ; 1.508)$ & $0.950(0.690 ; 1.309)$ & $1.074(0.615 ; 1.877)$ \\
\hline Current smoking, relative to none & $0.870(0.695 ; 1.089)$ & $0.923(0.719 ; 1.186)$ & $0.739(0.501 ; 1.090)$ \\
\hline Mild alcohol, relative to none & $1.037(0.858 ; 1.253)$ & $1.036(0.840 ; 1.277)$ & $1.371(0.998 ; 1.883)$ \\
\hline Moderate to severe alcohol, relative to none & $0.951(0.717 ; 1.263)$ & $0.952(0.698 ; 1.298)$ & $1.429(0.863 ; 2.364)$ \\
\hline
\end{tabular}




\begin{tabular}{|l|r|r|r|}
\hline Moderate caffeine, relative to none & $1.261(0.989 ; 1.608)$ & $1.125(0.858 ; 1.474)$ & $1.224(0.818 ; 1.830)$ \\
\hline Severe caffeine, relative to none & $1.073(0.738 ; 1.561)$ & $0.840(0.559 ; 1.262)$ & $1.052(0.556 ; 1.992)$ \\
\hline
\end{tabular}



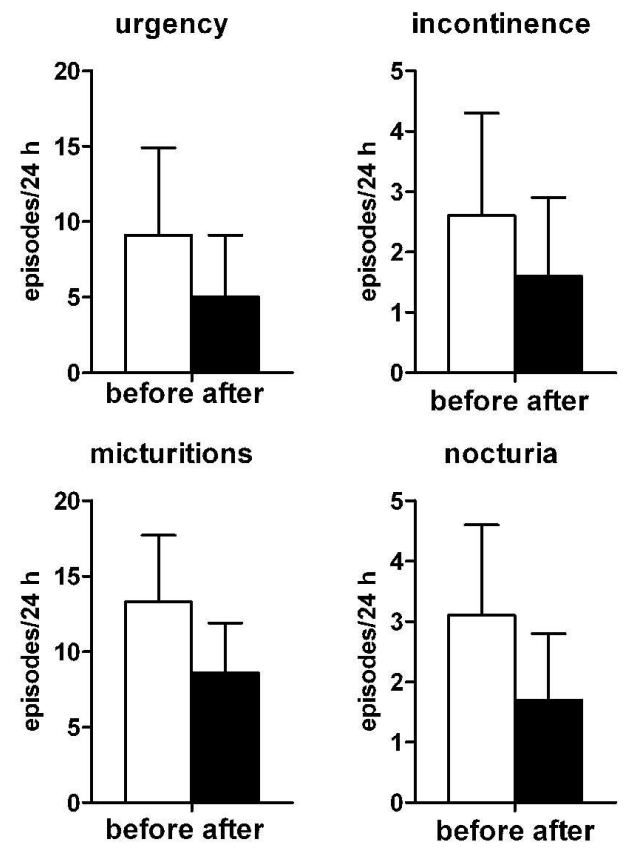

problem assessment

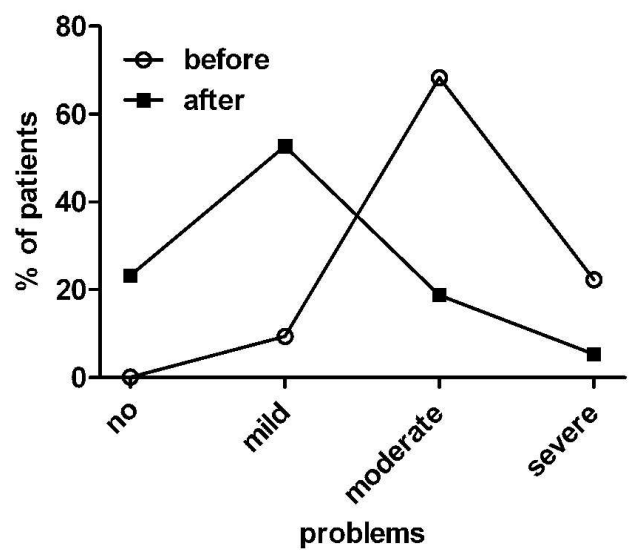

Figure 1 $120 \times 267 \mathrm{~mm}(600 \times 600 \mathrm{DPI})$ 